\title{
Left ventricular decompression in veno-arterial extracorporeal membrane oxygenation
}

\author{
Ashleigh Xie ${ }^{1}$, Paul Forrest ${ }^{2}$, Antonio Loforte ${ }^{3}$ \\ ${ }^{1}$ Royal Prince Alfred Hospital, Sydney, Australia; ${ }^{2}$ Department of Anaesthesia, Royal Prince Alfred Hospital, Sydney, Australia; ${ }^{3}$ Department of \\ Cardiothoracic, Transplantation and Vascular Surgery, S. Orsola Hospital, Bologna University, Bologna, Italy \\ Correspondence to: Dr. Ashleigh Xie, MD, MBBS. Royal Prince Alfred Hospital, Sydney, Australia. Email: ashleigh.xie@health.nsw.gov.au.
}

\begin{abstract}
Background: Despite the survival benefit of veno-arterial extracorporeal membrane oxygenation (VA-ECMO) for treatment of refractory cardiogenic shock, it can also have potentially deleterious effects of left ventricular overload and pulmonary edema. The objective of this review was to investigate the current evidence on the incidence, diagnosis, risk factors, prevention, and interventions for left ventricular overload in adult and pediatric VA-ECMO patients.

Methods: Five electronic databases, including MEDLINE, EMBASE, PubMed, Cochrane Central Register of Controlled Trials (CENTRAL), and Cochrane Database of Systematic Reviews, were searched for original published studies from their dates of inception to January 2018. All types of adult and pediatric studies that investigated LV overload in VA-ECMO and were published in the English language were reviewed. Exclusion criteria included abstracts and conference presentations.

Results: The reported incidence and sequelae of LV overload in VA-ECMO are highly variable, with presentations ranging from pulmonary arterial diastolic pressures of greater than $25 \mathrm{mmHg}$ and $\mathrm{LV}$ distention on echocardiography, to severe pulmonary edema, LV thrombosis, and refractory ventricular arrhythmias. Currently, there are no standardized diagnostic criteria or guidelines for the type and timing of intervention for LV overload. Techniques for LV decompression have included direct surgical LV venting with catheter insertion via sternotomy or a minimally invasive incision; percutaneous catheterization via a transaortic, transseptal, or transpulmonary approach; ventricular assist devices; and intra-aortic balloon pumps.

Conclusions: Left ventricular volume distention is a significant problem in VA-ECMO patients, with sequelae including myocardial ischemia, severe pulmonary edema, and intracardiac thrombosis. Further research is required on its incidence, diagnostic criteria, and risk factors, as well as the optimal timing and method for LV decompression, given the diversity of surgical and percutaneous techniques that are available.
\end{abstract}

Keywords: Ventricular distention; ventricular decompression; veno-arterial extracorporeal membrane oxygenation (VA-ECMO)

Submitted Oct 10, 2018. Accepted for publication Nov 20, 2018.

doi: $10.21037 /$ acs.2018.11.07

View this article at: http://dx.doi.org/10.21037/acs.2018.11.07

\section{Introduction}

While veno-arterial extracorporeal membrane oxygenation (VA-ECMO) effectively restores systemic blood flow in patients with cardiogenic shock, it has potentially deleterious effects on the left ventricle (LV).

VA-ECMO increases aortic root pressure and LV afterload, which can also lead to LV distention, especially if there is any aortic valve incompetence. $\mathrm{LV}$ distention is exacerbated by other sources of left atrial inflow (including bronchial and Thebesian veins, and residual pulmonary blood flow) (1-3). Hence VA-ECMO can decrease LV stroke volume, and increase LV end-systolic and enddiastolic volumes (4). 
Table 1 Range of diagnostic criteria for left ventricular overload

Diagnostic criteria

Clinical evidence of significant pulmonary edema, including pink frothy endotracheal secretions and CXR findings

Elevated central venous pressures

Elevated pulmonary arterial or pulmonary capillary wedge pressures

TTE or TOE evidence of LV distention, stasis, contrast 'smoke' sign, intracardiac thrombus, reduced ejection fraction, and intermittent or absent opening of the aortic valve

Cardiac catheterization findings including high LV filling pressures and stagnant contrast in the pulmonary arteries

Refractory ventricular arrhythmias such as ventricular tachycardia

CXR, chest X-ray; TTE, transthoracic echocardiogram; TOE, transoesophageal echocardiogram; LV, left ventricular.

Increased LV end-diastolic pressure in turn increases myocardial wall stress, which can cause ischemia and ventricular arrhythmias $(4,5)$. Furthermore, although VAECMO reduces right ventricular (RV) preload (via venous drainage), $\mathrm{RV}$ afterload may be increased due to pulmonary venous hypertension secondary to $L V$-volume overload (4). This can lead to pulmonary vascular injury and hemorrhage, acute respiratory distress syndrome, and severe pulmonary edema (6).

The combination of increased LV diastolic pressure and afterload may in some patients completely inhibit aortic valve opening. Reduced or absent $L V$ systolic ejection promotes intracardiac thrombus formation, which can cause fatal thromboembolism. LV thrombus extension into the pulmonary vein and distal pulmonary vasculature further limits the prospect of myocardial recovery and is a contraindication to long-term support with a ventricular assist device (VAD) (6,7).

\section{Methods}

Five electronic databases, including MEDLINE, EMBASE, PubMed, Cochrane Central Register of Controlled Trials (CENTRAL), and Cochrane Database of Systematic Reviews, were searched for original published studies from their dates of inception to January 2018. To maximize sensitivity of the search strategy, the following terms were used: "ecmo" or "extracorporeal membrane oxygenation" or "extracorporeal circulation" or "extracorporeal life support" AND "left ventric" or "left heart" AND "unload" or "decompress" or "distension" or "distention", as either keywords or MeSH terms. The reference lists of retrieved articles also were reviewed for additional relevant studies. Inclusion criteria included adult and pediatric studies that investigated LV overload in VA-ECMO and were published in the English language. All types of studies, including case reports and series, observational studies, review articles, and animal studies were included. Exclusion criteria included abstracts and conference presentations.

\section{Incidence}

The current data on the incidence of $\mathrm{LV}$ distention in adult and pediatric VA-ECMO patients is limited and highly variable (from $1 \%$ to $68 \%$ ) $(1,7,8)$. In a retrospective review of 134 adult VA-ECMO patients, Eliet et al. [2018] reported that $27(20 \%)$ required LV unloading, while Truby et al. [2017] found that 36 of 121 adults on VA-ECMO (30\%) had evidence of $L V$ distention, including nine patients requiring immediate venting $(7,9)$. The wide variation in reported rates of $L V$ distention is likely due to a lack of standard diagnostic criteria for LV overload, as well as variations in study populations and ECMO practice.

\section{Diagnosis}

Currently, there are no standardized guidelines for diagnosing LV distention in VA-ECMO patients. The studies included in the present review used one or more of the criteria summarized in Table 1 .

Truby and colleagues [2017] proposed diagnostic criteria for LV distention for use within the first two hours of VAECMO support (7). These criteria characterized patients as: 'no LV distention (LVD)', 'subclinical LVD'-not requiring immediate decompression, and 'clinical LVD'requiring emergency decompression (7). Subclinical LVD was diagnosed from chest X-ray (CXR) evidence of pulmonary edema and a pulmonary arterial diastolic blood pressure (PADBP) greater than $25 \mathrm{mmHg}$ (7). Clinical LVD was defined as severe pulmonary edema with worsening oxygenation, refractory ventricular arrhythmia, and/or significant LV stasis and increased LV end-diastolic diameter (LVEDD) on echocardiography requiring immediate LV decompression (7).

In regards to CXR evidence of pulmonary vascular injury during VA-ECMO support, Cheng et al. [2013] noted that 
the severity of pulmonary vascular injury may initially be under-recognized due to reduced pulmonary perfusion during VA-ECMO support, resulting in a relatively unremarkable CXR (6). However, once pulmonary blood flow is restored, radiological signs of florid pulmonary edema may become more apparent (6).

While transthoracic echocardiography (TTE) is useful in detecting $\mathrm{LV}$ distention in adults, diagnostic criteria are less well established in children. Eckhauser et al. [2014] demonstrated that TTE did not always provide obvious evidence of left heart hypertension in three peripheral VA-ECMO patients (aged 2 to 12 years) that were later demonstrated to have severe LV distention on cardiac catheterization (10). The echocardiographic parameters examined in this study included interatrial pressure gradient, left atrial diameter, and assessment of $\mathrm{LV}$ function (10). A major reason for this difficulty is that there are no widespread and standardized guidelines that specify which echocardiographic parameters are most useful in this pediatric setting. The authors in this study thereby developed a pediatric diagnostic echocardiographic algorithm derived from adult guidelines, though this clearly requires further investigation and application to larger patient sample sizes (10).

Serial brain natriuretic peptide (BNP) measurements have also been suggested as a means of monitoring $\mathrm{LV}$ distention and effectiveness of decompression, although this requires further investigation and validation (11).

\section{Risk factors and prevention}

The main risk factors for $\mathrm{LV}$ distention on VA-ECMO include:

* Severe LV failure $(1,7)$. VA-ECMO exacerbates LV failure by increasing LV afterload, which can cause systolic closure of the aortic valve;

* Aortic insufficiency (12). Any degree of aortic sufficiency may exacerbate LV overload. While mitral regurgitation alleviates $L V$ pressure overload, it worsens pulmonary edema $(5,7,13)$;

* High ECMO flow rate. The increase in afterload due to VA-ECMO is directly related to pump flow rate (12);

- Intravascular volume overload due to excessive fluid administration, as it may contribute to increased $\mathrm{LV}$ filling pressures (1).

LV distention may therefore be managed with vasodilators, inotropes, decreasing ECMO pump flow and lowering LV preload (with hemofiltration and judicious fluid administration). The adverse pulmonary effects of VA-ECMO can be counteracted with the use of low tidal volumes, increased positive end-expiratory pressures (PEEP), and early extubation when feasible $(1,12)$.

\section{Indications and timing for decompression}

There are no consensus guidelines as to when $L V$ venting should be performed. Some centers perform this prophylactically and routinely, particularly for pediatric patients (1). This is because infants have lower myocardial compliance than adults, which makes them more potentially more vulnerable to $L V$ distention and its sequelae (1). Other pediatric centers vent the LV if the PCWP is greater than $18 \mathrm{mmHg}$, even in the absence of severe pulmonary edema (14). However, as will be discussed, $L V$ venting itself is associated with significant risks.

Conversely, in adults, although some degree of LV distention probably occurs in nearly all VA-ECMO patients, this can be quite well tolerated with medical management alone (1). Generally recognized indications for $L V$ venting include:

* Aortic valve closure, due to the high risk of ventricular stasis and thrombosis (1);

* Severe aortic regurgitation, which will exacerbate LV overload and distention on VA-ECMO (1);

* Severe, refractory pulmonary edema secondary to LV overload (1);

* Patients who are not candidates for early left ventricular assist device (LVAD) support. Rupprecht et al. [2013] suggested that VA-ECMO with LV venting be used for patients with high recovery potential (e.g., acute myocarditis), while early LVAD implantation should be considered in patients with low recovery potential (1).

Other indications for $\mathrm{LV}$ decompression that have been reported include:

* Distended left atrium (LA) and LV with elevated pressures despite maximal pharmacological measures (15);

* Pulmonary hemorrhage (15);

* Evidence of elevated LV wall stress (15);

* Severe or persistent LV dysfunction (15).

\section{Techniques for decompression}

A wide variety of $L V$ venting techniques have been reported 


Table 2 Summary of left ventricular decompression techniques
Surgical
Vent insertion into:
Right upper pulmonary vein, with tip terminating in LA or LV
Pulmonary artery
LA appendage
LV apex
Approaches include sternotomy, anterolateral
mini-thoracotomy, subxiphoid incision, and
transdiaphragmatic approach
Percutaneous
Transaortic venting
Percutaneous transseptal venting, including:
Transseptal needle puncture
Balloon septostomy
Blade septostomy
Transseptal cannulation
Transpulmonary venting
Ventricular assist devices, primarily Impella
LA, left atrium; LV, left ventricle.
Intic balloon pump

in the literature. These can be categorized into surgical and percutaneous approaches, which are summarized in Table 2.

\section{Direct LV venting: surgical techniques}

This technique is most commonly performed via a preexisting sternotomy in patients with post-cardiotomy cardiogenic shock $(1,5)$. Typically, a vent is inserted through the right upper pulmonary vein (PV) with its tip terminating either in the LA or LV, and joined via a Y-connector to the venous access line of the ECMO circuit (5). Other sites for direct vent insertion include the LA appendage, LV apex, and pulmonary artery $(11,16)$. Surgical $L V$ venting provides decompression via large bore tubing that ensures adequate flow rates (17). It also enables direct monitoring of venous and LV arterial blood gases depending on the cannula tip position, which are useful in the detection of other ECMO complications, such as differential hypoxia [in combination with monitoring cerebral near-infrared spectrometry (NIRS)] (17).
Weymann et al. [2014] described LV venting via the right upper pulmonary vein at the time of ECMO cannulation, in 12 adult patients on central VA-ECMO, seven of whom survived to discharge (58\%) (17). Three studies of pediatric patients on central VA-ECMO have also shown that surgical $\mathrm{LV}$ vents for both elective and emergency indications (as discussed above) result in a rapid improvement in pulmonary edema and left heart distention $(11,18,19)$. In a study by Hacking et al. [2015] of pediatric central VAECMO, multivariate linear regression analysis showed that early elective decompression was associated with a shorter duration of ECMO support compared with emergency (late) decompression, although survival was not improved (18).

Several studies have compared elective $L V$ venting to no venting on VA-ECMO support. In a study of 48 adult patients by Schmack et al. [2017], 20 patients on central VAECMO support underwent $\mathrm{LV}$ decompression via the right upper PV (20). The LV vent was inserted during ECMO cannulation, and repeat echocardiography post venting showed a reduction in LV size compared to patients who did not undergo decompression (20). Patients with a vent also had significantly higher 30 -day survival (55\% versus $25 \%, \mathrm{P}=0.034)$, though there was no difference in mortality at 12 months and there were no differences in hepatic, renal, and pulmonary function (20). These results must be interpreted with caution, however, as several important baseline differences between the comparison groups were not controlled for, including younger age in the $L V$ vent group, and a higher proportion of post-cardiotomy shock and IABP insertions in the non $\mathrm{LV}$-vent group (20).

A study of peripheral and central VA-ECMO patients by Tepper et al. [2017] compared surgical LV venting with the Impella LVAD (16). Surgical vents were placed through the LV apex, right superior pulmonary vein, or the pulmonary artery. Unsurprisingly, a higher proportion of central VAECMO patients ( $\mathrm{n}=20$ versus $\mathrm{n}=6$ in the Impella group) and only two peripheral VA-ECMO patients (versus $n=16$ in the Impella group) comprised the surgical vent group (16). Patients with $L V$ venting had significantly lower pulmonary arterial diastolic pressure (PADP) at 48 hours than Impella patients, though central venous pressure (CVP) was similar and only five out of 16 surviving $L V$ vent patients had radiological evidence of improved pulmonary edema (16). Survival to 48 hours and 30 days was not significantly different between the groups. However, unadjusted baseline differences in the patient groups (central versus peripheral ECMO, and original indications for ECMO) were some of the many limitations of this study (16). Important 
complications of $\mathrm{LV}$ decompression via sternotomy include bleeding, risk of cardiac trauma and air embolism (16).

\section{Minimally invasive surgical vents}

A variety of minimally invasive approaches to $L V$ venting have been described, most commonly via anterolateral mini-thoracotomy. Centofanti et al. [2017] reported on 24 peripheral VA-ECMO patients with concomitant IABP who received a transapical $L V$ vent via a minithoracotomy (2). They demonstrated an immediate hemodynamic improvement [reduced CVP, increased achievable ECMO flow, increased mean arterial pressure (MAP) and improved mixed venous oxygen saturation $\left.\left(\mathrm{SvO}_{2}\right)\right](2)$. However, two patients required further surgery for chest wall bleeding from the transapical cannula (2). Keenan and colleagues [2016] described three patients on peripheral VA-ECMO who underwent echocardiographically-guided $\mathrm{LV}$ venting for severe pulmonary edema and LV dysfunction, with subsequent hemodynamic improvement and successful weaning (21).

Guirgis et al. [2010] described subxiphoid LV vent placement with a 20 French vent under direct vision in a peripheral VA-ECMO case for acute myocarditis, which was complicated by refractory pulmonary edema and pericardial tamponade (22). The subxiphoid incision used for a pericardial drain was re-opened and extended, and a 20 French vent was inserted into the $L V$ apex under direct vision (22). The patient's pulmonary edema resolved, a biventricular assist device (BiVAD) was implanted, and she survived to discharge (22).

\section{Other surgical approaches}

Eudailey et al. [2015] described a transdiaphragmatic approach to $L V$ venting in a patient who had an intraoperative cardiac arrest during a liver transplant (23). A diaphragmatic incision used for internal cardiac massage and was subsequently used to place a transapical $L V$ vent to treat $\mathrm{LV}$ distention and stasis that developed soon after initiating peripheral VA-ECMO (23). Subsequent TOE showed reduced $L V$ distention and increased LV ejection, with reduced vasopressor requirements (23).

In summary, there are a variety of effective surgical approaches to $L V$ venting, although these all have significant risks.

\section{Percutaneous LV venting}

\section{Catheter-based approaches}

\section{Transaortic vent}

Several authors have described a transaortic LV venting technique in peripheral VA-ECMO, where a variably sized (5 to 15 French) catheter is inserted via the femoral artery (contralateral to the ECMO arterial cannula), through the aortic valve and into the apex of the $\operatorname{LV}(3,24,25)$. This catheter is then connected to the venous access line of the ECMO circuit. Barbone and colleagues [2011] described this technique on ECMO initiation in three adults using a 7 French pigtail catheter (Johnson \& Johnson, New Jersey, USA), with echocardiographic evidence of reduced LV distention (24). Hong et al. [2016] utilized a similar echocardiography-guided technique with a 5 French pigtail catheter (PIG Perfoma, Merit Medical, South Jordan, USA) in seven adult peripheral VA-ECMO patients without procedural complications, and demonstrated significant improvements in LVEDD, LVEF, and MAP (25). Chocron et al. [2013] reported a similar technique utilizing the right subclavian artery and a Carmeda-coated 15 French Bio-Medicus cannula (Medtronic, Minneapolis, USA). Echocardiography (without specification as to whether TTE or TOE was used) demonstrated reduced LV distention and mitral regurgitation (3).

Transaortic venting has the advantage of rapid insertion (with mean procedural times of under 20 minutes) and is less invasive than surgical venting, although the potential risk of damage to the aortic valve over time is unknown (1).

\section{Percutaneous transseptal vent}

Percutaneous transseptal venting involves the creation of an atrial septal defect to decompress the LA. Various techniques for this have been described, including transseptal puncture with a Brockenbrough needle; blade septostomy; and balloon septostomy (1). In pediatric patients (e.g., neonates with a patent foramen ovale), balloon atrial septostomy is usually an adequate and straightforward procedure that can be performed at the bedside under echocardiographic guidance (26-28). In older patients, blade septostomy is preferred on the patent and thicker atrial septum (29). Another technique that has been used in both adults and children is transseptal cannulation, in which a catheter is inserted via the femoral vein (under fluoroscopic or echocardiographic guidance) into the LA 
through the interatrial septum, and then connected to the venous drainage limb of the ECMO circuit to provide decompression (30).

The above strategies in adult and pediatric patients on peripheral VA-ECMO have been shown to reduce PCWP, improve pulmonary edema, reduce LA pressure, improve ECMO output and LVEF, decrease LV distention, and improve ventricular arrhythmias refractory to medical management, as detailed in Tables $S 1$ and $S 2(8,10,12,14,26-45)$.

Atrial septostomy carries a risk of procedural failure. Lin et al. [2017] reported this in two out of 15 patientsthe first due to kinking of the cannula during attempted transseptal puncture and venting, and the second due to an inadequately sized ASD for decompression, which required a repeat septostomy (36). Other complications of septostomy include needle perforation of the LA and/or pulmonary vein, pericardial effusion, cardiac tamponade, and ventricular fibrillation (32). Furthermore, atrial septostomy may not prevent LV stasis or thrombosis, and may require subsequent repair $(6,46)$. Alkhouli et al. [2016] found that the majority (50-75\%) of iatrogenic ASDs spontaneously close by 6 to 12 months following simple septostomy (14). However, ASDs that persist longer than this have been associated with poorer survival and may require repair $(14,40,47)$.

A potential advantage of atrial stenting over simple blade or balloon septostomy is that it provides a controlled and unrestricted ASD that is less likely to spontaneously close over $(1,26)$. However, in the event of myocardial recovery and attempted weaning from ECMO, open surgical removal is usually required (1). Hence stenting may best be reserved for patients in whom myocardial recovery is not expected, and who will be bridged to either LVAD or transplantation (1). Other complications of atrial stenting include malpositioning or stent dislodgement (due to the thin and mobile atrial septum), LA perforation, damage to nearby structures such as the pulmonary veins, and thromboembolism $(1,26,48)$.

An advantage of transseptal cannulation is that (in common with atrial stenting), a controlled ASD can be tailored to the size of the patient, which has less risk of closure (26). Furthermore, the degree of left heart decompression can be adjusted, by either changing ECMO flow rates or clamping the cannula (26). Finally, due to the elasticity of the atrial septum, the residual ASD following cannula removal is usually small and amenable to device closure under fluoroscopy (26).

\section{Transpulmonary vent}

Transpulmonary venting involves the insertion of a variably sized (10 to 15 French) catheter via the right internal jugular vein into the pulmonary artery, which is then connected to the access line of the ECMO circuit (49). Avalli and colleagues [2011] described this technique in an adult patient on peripheral VA-ECMO patient with an LVEF of $10 \%$ and LV thrombus (50). Progress TTEs and TOEs by day 30 showed markedly improved LVEF (35-40\%) and reduced size of the LV thrombus, which resolved by discharge (50). Fouilloux et al. [2011] described an alternative approach in a 2-year-old girl on VA-ECMO, in whom LV unloading was successfully achieved using a 10 French catheter inserted via the femoral vein and inferior vena cava into the pulmonary trunk (51).

The potential advantages of this technique were first described by von Segesser et al. [2008] in animal models, and include decompression of the pulmonary circulation without reducing right ventricular ejection fraction, fewer complications, and short procedural times, although its relative efficacy remains unknown (50,52).

\section{VADs}

Unlike the vents described above, which are all passively driven, VADs actively pump blood from the LV. The most commonly reported VAD used to vent the LV during VAECMO support is the Impella (Abiomed, USA).

The Impella is a catheter-based axial flow pump that is introduced into the $\mathrm{LV}$ via the femoral artery, with outflow into the aorta (49). It is available in three sizes that provide flows of up to $2.5,3.5$ or $5 \mathrm{~L} / \mathrm{min}$ (53). Several adult and pediatric studies have shown that the use of an Impella device during VA-ECMO improves LVEDD, clinical and radiographic signs of pulmonary edema, and reduces PCWP and PVR $(6,7,9,13,46,54-57)$. There is limited evidence that this combination improves survival compared with VA-ECMO alone (56).

The Impella device simultaneously decompresses the $\mathrm{LV}$ and augments systemic blood flow, which protects the LV from blood stasis and thrombosis (6). For these reasons, the Impella is contraindicated in patients with $\mathrm{LV}$ thrombus or significant aortic insufficiency (6). In addition, the Impella flow should be maintained at its lowest effective level in order to minimize the risk of hemolysis (9). The Impella can provide ongoing LV support after weaning from ECMO, thereby extending the time available to decide 
upon potential bridging strategies (46).

Complications of the Impella device include hemolysis, bleeding, aortic valve insufficiency due to leaflet restriction by the device, limb ischemia, and migration of the pump head into the ascending aorta (e.g., from logrolling for nursing care) $(1,49)$. Pump failure has also been reported in $10 \%$ of patients (55). Alkhouli et al. [2016] has also suggested that the degree of $\mathrm{LV}$ unloading provided by the Impella may be insufficient for severe $\mathrm{LV}$ dysfunction and dilatation (14).

The TandemHeart device is another VAD that decompresses the LV. It comprises a centrifugal pump-assisted bypass between the LA and femoral artery. The access cannula is inserted percutaneously via the femoral vein and transseptally into the LA (49). The return cannula is inserted into the femoral artery, with the tip terminating at the aortic bifurcation (42). Given that this device can provide systemic flows, it can be used as an alternative to VA-ECMO for cardiogenic shock. Li and colleagues [2013] used a TandemHeart combined with an oxygenator to achieve haemodynamic stability in five adult patients in cardiogenic shock (58). Femoral access was used and the presence of the oxygenator avoided the need for transseptal puncture and its associated risks, including cardiac perforation, thromboembolism, and cannula dislodgement (58). In the present review, no study was found that examined the use of the TandemHeart with transseptal LA access as an exclusive strategy for LV decompression on VA-ECMO.

\section{Intra-aortic balloon pump (IABP)}

An IABP normally increases aortic diastolic pressures (and coronary perfusion) and reduces LV afterload. Although commonly used in conjunction with peripheral VA-ECMO, it should be noted that diastolic IABP inflation potentially interrupts retrograde peripheral VA-ECMO flow up to $60 \%$ of the time (9). The use of an IABP during peripheral VA-ECMO has also been shown to decrease aortic root pressure and coronary blood flow (59). Hence, an IABP may only have potential hemodynamic benefits in centrally cannulated VA-ECMO patients.

\section{Conclusions}

Left ventricular volume distention is a significant problem in VA-ECMO patients, with sequelae that include myocardial ischemia, severe pulmonary edema, and intracardiac thrombosis. There is limited data on many key issues, including its incidence, diagnostic criteria and timing for intervention. More research is needed in all these areas, and on the optimal method for LV decompression, given the variety of surgical and percutaneous treatment options that are available.

\section{Acknowledgements}

None.

\section{Footnote}

Conflicts of Interest: The authors have no conflicts of interest to declare.

\section{References}

1. Rupprecht L, Florchinger B, Schopka S, et al. Cardiac decompression on extracorporeal life support: a review and discussion of the literature. ASAIO J 2013;59:547-53.

2. Centofanti P, Attisani M, La Torre M, et al. Left Ventricular Unloading during Peripheral Extracorporeal Membrane Oxygenator Support: A Bridge To Life In Profound Cardiogenic Shock. J Extra Corpor Technol 2017;49:201-5.

3. Chocron S, Perrotti A, Durst C, et al. Left ventricular venting through the right subclavian artery access during peripheral extracorporeal life support. Interact Cardiovasc Thorac Surg 2013;17:187-9.

4. Lim HS, Howell N, Ranasinghe A. Extracorporeal Life Support: Physiological Concepts and Clinical Outcomes. J Card Fail 2017;23:181-96.

5. Meani P, Gelsomino S, Natour E, et al. Modalities and Effects of Left Ventricle Unloading on Extracorporeal Life support: a Review of the Current Literature. Eur J Heart Fail 2017;19:84-91.

6. Cheng A, Swartz MF, Massey HT. Impella to unload the left ventricle during peripheral extracorporeal membrane oxygenation. ASAIO J 2013;59:533-6.

7. Truby LK, Takeda K, Mauro C, et al. Incidence and Implications of Left Ventricular Distention During Venoarterial Extracorporeal Membrane Oxygenation Support. ASAIO J 2017;63:257-65.

8. Litwiński P, Demkow M, Sobieszczanska $M$, et al. Transseptal balloon atrial septostomy for decompression of the left atrium during extracorporeal membrane oxygenation support as a "bridge to transplantation" in dilated cardiomyopathy. Postepy Kardiol Interwencyjnej 
2017;13:72-4.

9. Eliet J, Gaudard P, Zeroual N, et al. Effect of Impella During Veno-Arterial Extracorporeal Membrane Oxygenation on Pulmonary Artery Flow as Assessed by End-Tidal Carbon Dioxide. ASAIO J 2018;64:502-7.

10. Eckhauser AW, Jones C, Witte MK, et al. Transthoracic echocardiographic predictors of left atrial hypertension in patients on venoarterial extracorporeal membrane oxygenation. World J Pediatr Congenit Heart Surg 2014;5:67-9.

11. Falkensammer CB, Heinle JS, Chang AC. Serial plasma BNP levels in assessing inadequate left ventricular decompression on ECMO. Pediatr Cardiol 2008;29:808-11.

12. Sidebotham D, Allen S, McGeorge A, et al. Catastrophic left heart distension following initiation of venoarterial extracorporeal membrane oxygenation in a patient with mild aortic regurgitation. Anaesth Intensive Care 2012;40:568-9.

13. Lim HS. The Effect of Impella CP on Cardiopulmonary Physiology During Venoarterial Extracorporeal Membrane Oxygenation Support. Artif Organs 2017;41:1109-12.

14. Alkhouli M, Narins CR, Lehoux J, et al. Percutaneous Decompression of the Left Ventricle in Cardiogenic Shock Patients on Venoarterial Extracorporeal Membrane Oxygenation. J Card Surg 2016;31:177-82.

15. Ong CS, Hibino N. Left heart decompression in patients supported with extracorporeal membrane oxygenation for cardiac disease. Postepy Kardiol Interwencyjnej 2017;13:1-2.

16. Tepper S, Masood MF, Baltazar Garcia M, et al. Left Ventricular Unloading by Impella Device Versus Surgical Vent During Extracorporeal Life Support. Ann Thorac Surg 2017;104:861-7.

17. Weymann A, Schmack B, Sabashnikov A, et al. Central extracorporeal life support with left ventricular decompression for the treatment of refractory cardiogenic shock and lung failure. J Cardiothorac Surg 2014;9:60.

18. Hacking DF, Best D, d'Udekem Y, et al. Elective decompression of the left ventricle in pediatric patients may reduce the duration of venoarterial extracorporeal membrane oxygenation. Artif Organs 2015;39:319-26.

19. Sandrio S, Springer W, Karck M, et al. Extracorporeal life support with an integrated left ventricular vent in children with a low cardiac output. Cardiol Young 2014;24:654-60.

20. Schmack B, Seppelt P, Weymann A, et al. Extracorporeal life support with left ventricular decompression-improved survival in severe cardiogenic shock: results from a retrospective study. PeerJ 2017;5:e3813.

21. Keenan JE, Schechter MA, Bonadonna DK, et al. Early Experience with a Novel Cannulation Strategy for Left Ventricular Decompression during Nonpostcardiotomy Venoarterial ECMO. ASAIO J 2016;62:e30-4.

22. Guirgis M, Kumar K, Menkis AH, et al. Minimally invasive left-heart decompression during venoarterial extracorporeal membrane oxygenation: an alternative to a percutaneous approach. Interact Cardiovasc Thorac Surg 2010;10:672-4.

23. Eudailey KW, Yi SY, Mongero LB, et al. Transdiaphragmatic left ventricular venting during peripheral venous-arterial extracorporeal membrane oxygenation. Perfusion 2015;30:701-3.

24. Barbone A, Malvindi PG, Ferrara P, et al. Left ventricle unloading by percutaneous pigtail during extracorporeal membrane oxygenation. Interact Cardiovasc Thorac Surg 2011;13:293-5.

25. Hong TH, Byun JH, Lee HM, et al. Initial Experience of Transaortic Catheter Venting in Patients with Venoarterial Extracorporeal Membrane Oxygenation for Cardiogenic Shock. ASAIO J 2016;62:117-22.

26. Hlavacek AM, Atz AM, Bradley SM, et al. Left atrial decompression by percutaneous cannula placement while on extracorporeal membrane oxygenation. J Thorac Cardiovasc Surg 2005;130:595-6.

27. Johnston TA, Jaggers J, McGovern JJ, et al. Bedside transseptal balloon dilation atrial septostomy for decompression of the left heart during extracorporeal membrane oxygenation. Catheter Cardiovasc Interv 1999;46:197-9.

28. Koenig PR, Ralston MA, Kimball TR, et al. Balloon atrial septostomy for left ventricular decompression in patients receiving extracorporeal membrane oxygenation for myocardial failure. J Pediatr 1993;122:S95-9.

29. Cheung MM, Goldman AP, Shekerdemian LS, et al. Percutaneous left ventricular "vent" insertion for left heart decompression during extracorporeal membrane oxygenation. Pediatr Crit Care Med 2003;4:447-9.

30. Bernhardt AM, Hillebrand M, Yildirim Y, et al. Percutaneous left atrial unloading to prevent pulmonary oedema and to facilitate ventricular recovery under extracorporeal membrane oxygenation therapy. Interact Cardiovasc Thorac Surg 2018;26:4-7.

31. Alhussein M, Osten M, Horlick E, et al. Percutaneous left atrial decompression in adults with refractory cardiogenic shock supported with veno-arterial extracorporeal membrane oxygenation. J Card Surg 2017;32:396-401. 
32. Dahdouh Z, Roule V, Lognone T, et al. Atrial septostomy in cardiogenic shock related to $\mathrm{H} 1 \mathrm{~N} 1$ infection. Acute Card Care 2013;15:7-9.

33. Dahdouh Z, Roule V, Sabatier R, et al. Extra-corporeal life support, transradial thrombus aspiration and stenting, percutaneous blade and balloon atrioseptostomy, all as a bridge to heart transplantation to save one life. Cardiovasc Revasc Med 2012;13:241-5.

34. Jumean M, Pham DT, Kapur NK. Percutaneous biatrial extracorporeal membrane oxygenation for acute circulatory support in advanced heart failure. Catheter Cardiovasc Interv 2015;85:1097-9.

35. Lee SI, Lee SY, Choi CH, et al. Left Heart Decompression in Acute Complicated Myocardial Infarction During Extracorporeal Membrane Oxygenation. J Intensive Care Med 2017;32:405-8.

36. Lin YN, Chen YH, Wang HJ, et al. Atrial Septostomy for Left Atrial Decompression During Extracorporeal Membrane Oxygenation by Inoue Balloon Catheter. Circ J 2017;81:1419-23.

37. Peterss S, Pfeffer C, Reichelt A, et al. Extracorporeal life support and left ventricular unloading in a non-intubated patient as bridge to heart transplantation. Int J Artif Organs 2013;36:913-6.

38. Aiyagari RM, Rocchini AP, Remenapp RT, et al. Decompression of the left atrium during extracorporeal membrane oxygenation using a transseptal cannula incorporated into the circuit. Crit Care Med 2006;34:2603-6.

39. Cofer BR, Warner BW, Stallion A, et al. Extracorporeal membrane oxygenation in the management of cardiac failure secondary to myocarditis. J Pediatr Surg 1993;28:669-72.

40. Eastaugh LJ, Thiagarajan RR, Darst JR, et al. Percutaneous left atrial decompression in patients supported with extracorporeal membrane oxygenation for cardiac disease. Pediatr Crit Care Med 2015;16:59-65.

41. Kim HE, Jung JW, Shin YR, et al. Left Atrial Decompression by Percutaneous Left Atrial Venting Cannula Insertion during Venoarterial Extracorporeal Membrane Oxygenation Support. Korean J Thorac Cardiovasc Surg 2016;49:203-6.

42. Kredel M, Kunzmann S, Schlegel PG, et al. Double Peripheral Venous and Arterial Cannulation for Extracorporeal Membrane Oxygenation in Combined Septic and Cardiogenic Shock. Am J Case Rep 2017;18:723-7.

43. Swartz MF, Smith F, Byrum CJ, et al. Transseptal catheter decompression of the left ventricle during extracorporeal membrane oxygenation. Pediatr Cardiol 2012;33:185-7.

44. Veeram Reddy SR, Guleserian KJ, Nugent AW. Transcatheter removal of atrial septal stent placed to decompress left atrium with VA ECMO. Catheter Cardiovasc Interv 2015;85:1021-5.

45. Ward KE, Tuggle DW, Gessouroun MR, et al. Transseptal decompression of the left heart during ECMO for severe myocarditis. Ann Thorac Surg 1995;59:749-51.

46. Abu Saleh WK, Mason P, Al Jabbari O, et al. Successful use of surgically placed impella 5.0: And central extracorporeal membrane oxygenation circuit in a patient with postcardiotomy shock. Tex Heart Inst J 2015;42:569-71.

47. Schueler R, Öztürk C, Wedekind JA, et al. Persistence of Iatrogenic Atrial Septal Defect After Interventional Mitral Valve Repair With the MitraClip System: A Note of Caution. JACC Cardiovasc Interv 2015;8:450-9.

48. Haynes S, Kerber RE, Johnson FL, et al. Left heart decompression by atrial stenting during extracorporeal membrane oxygenation. Int J Artif Organs 2009;32:240-2.

49. Meani P, Natour E, Pappalardo F, et al. Left ventricle unloading in veno-arterial ECMO support: Literature review for an unanswered dilemma. Eur J Heart Fail 2017;19:64-6.

50. Avalli L, Maggioni E, Sangalli F, et al. Percutaneous leftheart decompression during extracorporeal membrane oxygenation: an alternative to surgical and transeptal venting in adult patients. ASAIO J 2011;57:38-40.

51. Fouilloux V, Lebrun L, Mace L, et al. Extracorporeal membranous oxygenation and left atrial decompression: a fast and minimally invasive approach. Ann Thorac Surg 2011;91:1996-7.

52. von Segesser L, Dembitsky W, Ferrari E, et al. A simple way to decompress the left ventricle during veno-arterial bypass. Thorac Cardiovasc Surg 2008;56:337-41.

53. Cena M, Karam F, Ramineni R, et al. New Impella Cardiac Power Device Used in Patient with Cardiogenic Shock due to Nonischemic Cardiomyopathy. Int J Angiol 2016;25:258-62.

54. Koeckert MS, Jorde UP, Naka Y, et al. Impella LP 2.5 for left ventricular unloading during venoarterial extracorporeal membrane oxygenation support. J Card Surg 2011;26:666-8.

55. Moazzami K, Dolmatova EV, Cocke TP, et al. Left Ventricular Mechanical Support with the Impella during Extracorporeal Membrane Oxygenation. J Tehran Heart Cent 2017;12:11-4. 
56. Pappalardo F, Schulte C, Pieri M, et al. Concomitant implantation of Impella ${ }^{\circledR}$ on top of veno-arterial extracorporeal membrane oxygenation may improve survival of patients with cardiogenic shock. Eur J Heart Fail 2017;19:404-12.

57. Vlasselaers D, Desmet M, Desmet L, et al. Ventricular unloading with a miniature axial flow pump in combination with extracorporeal membrane oxygenation. Intensive Care Med 2006;32:329-33.

58. Li YW, Rosenblum WD, Gass AL, et al. Combination use

Cite this article as: Xie A, Forrest P, Loforte A. Left ventricular decompression in veno-arterial extracorporeal membrane oxygenation. Ann Cardiothorac Surg 2019;8(1):918. doi: 10.21037/acs.2018.11.07 of a TandemHeart with an extracorporeal oxygenator in the treatment of five patients with refractory cardiogenic shock after acute myocardial infarction. Am J Ther 2013;20:213-8.

59. Bělohlávek J, Mlček M, Huptych $M$, et al. Coronary versus carotid blood flow and coronary perfusion pressure in a pig model of prolonged cardiac arrest treated by different modes of venoarterial ECMO and intraaortic balloon counterpulsation. Crit Care 2012;16:R50. 


\begin{tabular}{|c|c|c|c|c|c|c|}
\hline Author & Decompression technique(s) & Year & Sample & VA-ECMO type & Diagnosis/indication for LV decompression & Results and learning points \\
\hline Abu Saleh & Impella 5.0 & 2015 & 1 & Central & $\begin{array}{l}\text { On POD5-increased CV and PA pressures, TEE showing LV dilatation } \\
\text { with } 10 \% \mathrm{EF}\end{array}$ & Successful LV unloading, bridged to Impella, weaned off all supports \\
\hline Alhussein & Atrial balloon septostomy with transseptal needle & 2017 & 7 & Peripheral & $\begin{array}{l}\text { TEE with LV dilatation and echo contrast 'smoke', } \\
\text { 'evidence of pulmonary edema despite medical therapy' }\end{array}$ & $\begin{array}{l}\text { Prior attempted medical therapy - inotropes, diuresis/dialysis. All initially improved with CXR. } \\
\text { Procedural success } 100 \% .5 / 7 \text { survived to hospital discharge, only } 1 \text { completely recovered } \\
\text { biventricular function. A further } 2 \text { were transplanted, } 1 \text { received an LVAD, and } 1 \text { received a } \\
\text { Centriliag VAD }\end{array}$ \\
\hline Alkhouli & $\begin{array}{l}\text { Transseptal LV cannula }+/ \text { - balloon septostomy } \\
\text { via femoral catheterisation }\end{array}$ & 2016 & 4 & Peripheral & Persistent pulmonary edema & $\begin{array}{l}\text { Reduced PCWP and resolved pulmonary edema in all patients. } 2 / 4 \text { survived to discharge. } \\
\text { Residual ASD underwent patch repair or monitored with plan for closure }\end{array}$ \\
\hline Cheng & Impella 2.5 & 2013 & 5 & Peripheral & $\begin{array}{l}\text { TEE with enlarged and dysfunctional LV with EF }<20 \% \text {; evidence of LV stasis } \\
\text { with echo 'smoke'; intermittent or absent opening of AV; PCWP }>18 \mathrm{mmHg}\end{array}$ & $\begin{array}{l}\text { Successful LV unloading in } 4 / 5 \text { patients and transition to long term LVAD. } 1 \text { death from } \\
\text { progressive multiorgan failure. No major complications from Impella }\end{array}$ \\
\hline Avalli & $\begin{array}{l}\text { Percutaneous pulmonary artery cannulation, connected } \\
\text { to venous ECMO limb. IABP later added }\end{array}$ & 2011 & 1 & Peripheral & $\begin{array}{l}\text { Prior to ECMO institution - TEE showing large LV thrombus. LV venting done } \\
\text { to prevent thromboembolism }\end{array}$ & $\begin{array}{l}\text { Advantages of this approach include fewer complications compared to blade septostomy or } \\
\text { transseptal stenting, less expensive than axial pump, and easier and faster to perform }\end{array}$ \\
\hline Barbone & TEE-guided percutaneous transaortic LV pigtail catheter & 2011 & 3 & Peripheral & $\begin{array}{l}\text { Inserted in catheterisation lab at the same time as ECMO initiation; evidence } \\
\text { of LV dilatatation and pre-ECMO LV thrombus reported in } 1 \text { patient }\end{array}$ & LV volume overload can be worsened in peripheral versus central ECMO \\
\hline Bernhardt & $\begin{array}{l}\text { TEE- and fluoroscopic-guided percutaneous transseptal } \\
\text { Tandem Heart cannula inserted into LA }\end{array}$ & 2017 & 1 & Peripheral & Preexisting LV thrombus and closed AV despite inotropes & $\begin{array}{l}\text { Recovered and weaned without neurological sequelae, stably impaired LV and stable LV thrombus, } \\
\text { nil ASD }\end{array}$ \\
\hline Centofanti & Minimally invasive (thoracotomy) transapical LV vent and IABP & 2017 & 24 & Peripheral & To 'relieve LV distention, pulmonary congestion, and avoid LV thrombosis' & $\begin{array}{l}15 / 24 \text { patients survived to } 30 \text { days. Immediate haemodynamic improvement post transapical vent, } \\
\text { shown by increased ECMO output, reduced CVP, increased MAP, and increased SvO2. } \\
2 / 24 \text { patients required surgrical revision for chest wall bleeding from transapical cannula }\end{array}$ \\
\hline Chocron & $\begin{array}{l}\text { Percutaneous (via right subclavian artery) LV vent, } \\
\text { connected to venous ECMO limb }\end{array}$ & 2013 & 1 & Peripheral & TEE with LV dilatation with grade $2 \mathrm{MV}$ regurgitation & Weaned from ECMO but developed postanoxic coma and died 2 months later \\
\hline Dahdouh & Percutaneous blade and balloon atrial septostomy & 2012 & 1 & Peripheral & $\begin{array}{l}\text { Right heart catheterisation showing high LV filling pressures and stagnant } \\
\text { contrast in pulmonary arteries }\end{array}$ & $\begin{array}{l}\text { Immediately improved pulmonary edema and reduced LA pressures, improved ECMO output, } \\
\text { survived to discharge }\end{array}$ \\
\hline Dahdouh & Percutaneous blade and balloon atrial septostomy & 2013 & 1 & Peripheral & $\begin{array}{l}\text { Right heart catheterisation showing high LV filling pressures and stagnant } \\
\text { contrast in pulmonary arteries }\end{array}$ & $\begin{array}{l}\text { Immediately improved pulmonary edema and reduced LA pressures, improved ECMO output, no } \\
\text { neurologic sequelae and LVEF improved to } 75 \% \text { with non-significant residual shunt by discharge }\end{array}$ \\
\hline Eliet & Impella 2.5 and 5.0 & 2018 & 11 & Peripheral & $\begin{array}{l}\text { Severe LV overload with severe pulmonary edema, echo showing heavy } \\
\text { spontaneous contrast in left heart, or loss of LV ejection (aortic velocity-time } \\
\text { integral }<5 \mathrm{~cm} \text {, or pulse pressure }<10 \mathrm{mmH} \text { ) including loss of AV opening }\end{array}$ & $\begin{array}{l}\text { Proportional increases in pulmonary velocity-time integral and } \mathrm{EtCO}_{2} \text {, and decrease in } \mathrm{LVEDD} \text { during } \\
\text { Impeella flow increase }\end{array}$ \\
\hline Eudailey & $\begin{array}{l}\text { Transdiaphragmatic LV vent (emergent incision made } \\
\text { intraoperatively for manual cardiac massage post arrest) }\end{array}$ & 2015 & 1 & Peripheral & TEE showing LV distention, dysfunction, and stasis & $\begin{array}{l}\text { TEE showing complete LV decompression, clinical improvement with decreased vasopressor } \\
\text { requirements and normalisation of LVEF. Repaired diaphragm via patch cruroplasty }\end{array}$ \\
\hline Guirgis & Minimally invasive (subxiphoid) apical LV vent & 2010 & 1 & Peripheral & Severe pulmonary edema, acutely elevated CVP, echo showing akinetic LV & $\begin{array}{l}\text { Lack of proper equipment (e.g., specialised catheters, hybrid theatre) and trained staff precluded } \\
\text { percutaneous decompression. Improvement of pulmonary edema post decompression, } \\
\text { weaned to LVAD }\end{array}$ \\
\hline Haynes & $\begin{array}{l}\text { Percutaneous pulmonary venous puncture, with } \\
\text { balloonn-expandable stent placed across atrial septum } \\
\text { under fluoroscopic and echo guidance }\end{array}$ & 2009 & 1 & $\begin{array}{l}\text { Peripheral. Two venous } \\
\text { cannulae in femoral and } \\
\text { right internal jugular vein. }\end{array}$ & $\begin{array}{l}\text { Haemorrhagic pulmonary edema, echo showing LV distention and } \\
\text { spontaneous contrast in LA, low mixed venous saturation of } 20 \%\end{array}$ & $\begin{array}{l}\text { Adults can have a thickened atrial septum, more difficult to penetrate and not suitable for pigtail } \\
\text { catheters. Improved mixed venous saturations and reduced left heart size. Patient died } 9 \text { hours post } \\
\text { decompression however (brain death), authors believe likely due to original arrest }\end{array}$ \\
\hline Hong & $\begin{array}{l}\text { TTE guided percutaneous transaortic catheter } \\
\text { vent into LV. IABP inserted into } 1 \text { of } 7 \text { patients }\end{array}$ & 2016 & 7 & Peripheral & $\begin{array}{l}\text { LV dysfunction with LVEF }<25 \% \text {, persistent pulmonary edema on CXR, or LV } \\
\text { asystole on } T E E\end{array}$ & $\begin{array}{l}\text { Nil procedural complications, } 4 / 7 \text { patients survived to discharge. Significant reduction in LVED and } \\
\text { improved LVEF, and increased MAP in survivors }\end{array}$ \\
\hline $\mathrm{Hu}$ & IABP & 2015 & 2 & Peripheral & LV dilatation, reduced LVEF, ventricular tachycardia & $\begin{array}{l}\text { Improved LVEF and pulse pressure, nil recurrence of ventricular tachycardia, improved lactate. } \\
\text { 1/2 patients survived }\end{array}$ \\
\hline Jumean & $\begin{array}{l}\text { Fluoroscopy-guided percutaneous transseptal TandemHeart } \\
\text { cannula inserted into LA }\end{array}$ & 2015 & 1 & Peripheral & $\begin{array}{l}\text { Preexisting LV thrombus, TEE showing LV distention, recurrent ventricular } \\
\text { arrythmias }\end{array}$ & $\begin{array}{l}\text { Reduced biventricular filling pressures, improved distention, resolution of refractory ventricular } \\
\text { arrhythmias. Bridged to LVAD, but developed new right heart thrombus and died } 2 \text { weeks later from } \\
\text { cardiogenic shock }\end{array}$ \\
\hline Keenan & $\begin{array}{l}\text { Minimally invasive (right minithoracotomy) LV vent, } \\
\text { TEE-guided. One patient had preexisting IABP }\end{array}$ & 2016 & 3 & Peripheral & Severe pulmonary edema with LV dysfunction & $\begin{array}{l}\text { Improved LV function and haemodynamics in one patient; } 1 / 3 \text { patients survived. Potential } \\
\text { complications include mediastinitis and bleeding }\end{array}$ \\
\hline Koeckert & Impella 2.5 & 2011 & 1 & Peripheral & Severe pulmonary edema and LV distention & Improved pulmonary edema on CXR and reduced LVEDD. Survived to discharge home \\
\hline Lee & Percutaneous balloon atrial septostomy & 2017 & 1 & Peripheral & Worsening pulmonary edema and TTE showing LV distention & Improved pulmonary edema and LV distention; reduced cardiac enzymes. Survived to discharge \\
\hline Lim & Impella CP & 2017 & 6 & Peripheral & NR & $\begin{array}{l}\text { Reduced PAWP and PVR. 2/6 patients had complications from Impella - haemolysis, bleeding from } \\
\text { insertion site }\end{array}$ \\
\hline Lin & Fluoroscopic-guided percutaneous balloon atrial septostomy & 2017 & 15 & Peripheral & Refractory pulmonary edema & $\begin{array}{l}\text { Failed transseptal puncture in } 1 / 15 \text { patients (kinking of device and cannula); repeat procedure } \\
\text { required in 1/15 patients. } 8 / 15 \text { patients survived. Improved pulmonary edema on imaging }\end{array}$ \\
\hline Litwinski & Fluoroscopic-guided percutaneous balloon atrial septostomy & 2017 & 1 & Central & $\begin{array}{l}\text { Refractory pulmonary edema, echo showing distended and akinetic LV with } \\
\text { lack of AV opening }\end{array}$ & $\begin{array}{l}\text { Nil procedural complications. Improved ECMO output and resolution of pulmonary edema. Survived } \\
\text { to discharge }\end{array}$ \\
\hline Moazzami & Impella 2.5.5/10 patients had prior IABP & 2017 & 10 & $\begin{array}{l}\text { Peripheral }(8 / 10), \\
\text { central }(2 / 10)\end{array}$ & NR & $\begin{array}{l}\text { Immediate reduction in RA pressure and PCWP, decreased LVEDD. } 5 / 10 \text { survivors. 1/10 had fatal } \\
\text { device malfunction and } 1 / 10 \text { had severe bleeding from Impella insertion site }\end{array}$ \\
\hline Pappalardo & $\begin{array}{l}\text { Impella } 2.5 \text { and CP. IABP use in a minority was adjusted for in } \\
\text { propensity matching }\end{array}$ & 2017 & $\begin{array}{l}157 \text { (NA-ECMO and } \\
\text { Impella, } n=34 ; \\
\text { VA-ECMO only, } n=123)\end{array}$ & Peripheral & $\begin{array}{l}\text { Echo showing impaired LV unloading or stasis;s 'impending' LV thrombosis, } \\
\text { pulmonary edema, and/or significant aortic regurgitation }\end{array}$ & $\begin{array}{l}\text { Greater rates of haemolysis and need for haemodialysis, and longer duration of VA-ECMO and } \\
\text { ventilation in Impella and VA-ECMO group. Reduced mortality, higher rate of bridging to recovery or } \\
\text { next therapy with Impella and VA-ECMO group }\end{array}$ \\
\hline Peterss & $\begin{array}{l}\text { Percutaneous Brockenbrough needle and balloon atrial } \\
\text { septostomy }\end{array}$ & 2013 & 1 & Peripheral & LV dysfunction and refractory pulmonary edema & $\begin{array}{l}\text { Immediate improvement in pulmonary edema on CXR, bridged to transplant and survived to } \\
\text { discharge and at 6-month follow-up }\end{array}$ \\
\hline Schmack & Right pulmonary vein puncture with cannula inserted into LV & 2017 & 48 & $\begin{array}{l}\text { Peripheral (without LV vent, } \\
\mathrm{n}=10 \text { ), central (with LV vent, } \\
\mathrm{n}=20 \text {; without, } \mathrm{n}=18 \text { ) }\end{array}$ & NR, LV vent placed at same time as central ECMO & Improved 30-day survival in central ECMO with LV vent but nil difference in long term \\
\hline Sidebotham & Percutaneous atrial septostomy (technique NS) & 2012 & 1 & Peripheral & $\begin{array}{l}\text { Within } 5 \text { minutes of starting ECMO, TEE showing severe LV distention, } \\
\text { loss of AV closure, and clinical evidence of pulmonary edema }\end{array}$ & $\begin{array}{l}\text { Nil procedural complications. LV remained distended however with open AV and evidence of LV } \\
\text { thrombus. Patient died }\end{array}$ \\
\hline Tepper & $\begin{array}{l}\text { Impella 2.5, 5.0, or CP }(\mathrm{n}=23) \text {, versus } L \mathrm{~V} \text { vent }(\mathrm{n}=22) \text { placed } \\
\text { through } L V \text { apex/right pulmonary vein/pulmonary artery }\end{array}$ & 2017 & 45 & $\begin{array}{l}\text { Peripheral }(n=18), \\
\text { central }(n=27)\end{array}$ & $\begin{array}{l}\text { NR. } 1 \text { patient had simultaneous ECMO and Impella placement, and } 3 \text { had } \\
\text { preexisting Impella }\end{array}$ & $\begin{array}{l}\text { CVP and LFTs significantly reduced in Impella, but not LV vent group. PADP significantly reduced } \\
\text { post } 48 \mathrm{~h} \text { in both groups. Pulmonary edema on CXR improved in } 13 / 20 \text { surviving Impella patients, } \\
\text { and } 5 / 116 \text { surviving vent patients. Similar } 48 \mathrm{~h} \text { survival and ICU discharge }\end{array}$ \\
\hline Truby & Impella 2.5 and CP. IABP prior to VA-ECMO in $40 \%$ of patients & 2017 & $\begin{array}{c}121 \\
\text { (19 decompressed) }\end{array}$ & Peripheral & $\begin{array}{l}\text { Subclinical LVD: pulmonary edema on CXR and PADBP }>25 \mathrm{mmHg} \\
\text { within first } 2 \mathrm{~h} \text { of VA-ECMO; clinical LVD: requirement for immediate LV } \\
\text { decompression due to pulmonary edema, refractory ventricular arrythmia, or } \\
\text { significant stagnation of blood in LV }\end{array}$ & $\begin{array}{l}\text { Reduced PADP, LVED in LVD patients. Similar survival. Lower rate of myocardial recovery and } \\
\text { increased need for device transition in surviving LVD patients }\end{array}$ \\
\hline Weymann & LV vent via right pulmonary vein & 2014 & 12 & Central & Elective & Overall survival to end of study $58.3 \%$ \\
\hline
\end{tabular}




\begin{tabular}{|c|c|c|c|c|c|c|}
\hline Author & Decompression Technique(s) & Year & Sample & VA-ECMO type & Diagnosis/indication for LV decompression & Results and learning points \\
\hline Aiyagari & $\begin{array}{l}\text { Fluoroscopy-guided percutaneous transseptal drain insertion into } \\
\text { LA }\end{array}$ & 2006 & 7 & Peripheral & $\begin{array}{l}\text { TTE showing LA hypertension (22 to } 45 \mathrm{mmHg} \text { ), acute respiratory distress syndrome } \\
\text { with massive hemoptysis, CXR with severe pulmonary edema }\end{array}$ & $\begin{array}{l}\text { Procedural success in } 5 / 7 \text { patients, survival to discharge in } 3 / 7 \text { patients. Reinforced importance } \\
\text { of adequately sized left atrial drain for sufficient decompression }\end{array}$ \\
\hline Cheung & TTE-guided percutaneous transatrial LV vent & 2003 & 1 & Peripheral & TEE showing LA distention and impaired LVEF & $\begin{array}{l}\text { TE showing LV decompression. Survived to heart transplant. Balloon atrial septostomy is } \\
\text { preferred in infants, and blade septostomy in older patients }\end{array}$ \\
\hline Cofer & $\begin{array}{l}\text { Fluoroscopy or TTE-guided blade and/or balloon atrial } \\
\text { septostomy }\end{array}$ & 1993 & 3 & Peripheral & $\begin{array}{l}\text { TE showing left heart distention and elevated pressures, CXR showing pulmonary } \\
\text { edema }\end{array}$ & $\begin{array}{l}\text { Reduction in LA and pulmonary pressures, clinical improvement in pulmonary edema. Survival } \\
\text { in } 2 / 3 \text { patients with TTE showing persistent ASD }\end{array}$ \\
\hline Eastaugh & LA venting, transseptal balloon dilatation, or transseptal stenting & 2015 & 44 & Peripheral & $\begin{array}{l}\text { ME showing left heart distention, CXR and clinical signs of cardiogenic pulmonary } \\
\text { edema or haemorhage }\end{array}$ & $\begin{array}{l}\text { Significant reduction in LA pressure in } 22 / 38 \text { measured patients, improvement in CXR } \\
\text { appearance in } 30 / 41 \text {, survival in } 31 / 44 \text { patients. Persistent ASD in } 5 \text { patients with } 2 \text { requiring } \\
\text { device closure }\end{array}$ \\
\hline Eckhauser & $\begin{array}{l}\text { Fluoroscopy-guided percutaneous balloon septostomy, with } \\
\text { additional transseptal cannulation in } 1 \text { patient }\end{array}$ & 2014 & 3 & Peripheral & $\begin{array}{l}\text { CXR and clinical evidence of severe pulmonary edema and haemorrhage, TE showing } \\
\text { stagnant flow in LV with severe MR }\end{array}$ & $\begin{array}{l}\text { Improvement in LA pressures, survival in } 2 / 3 \text { patients. Development of a new TTE algorithmic } \\
\text { assessment tool to more accurately detect LA hypertension in children }\end{array}$ \\
\hline Falkensammer & Surgical insertion (sternotomy) of LA cannula via LA appendage & 2008 & 1 & Central & TE showing left heart distention, depressed LV function, elevated BNP level & $\begin{array}{l}\text { Reduction in left heart distention and BNP levels. Survival to discharge. Serial BNP levels as a } \\
\text { marker of left heart distention on VA-ECMO. }\end{array}$ \\
\hline Fouilloux & $\begin{array}{l}\text { Fluoroscopy-guided percutaneous cannula insertion into } \\
\text { pulmonary trunk }\end{array}$ & 2011 & 1 & Peripheral & $\begin{array}{l}\text { CXR and clinical evidence of severe pulmonary edema and haemorrhage, TE showing } \\
\text { severe LA dilatatation with large LA thrombus }\end{array}$ & $\begin{array}{l}\text { Reduction in left heart distention, clinical and radiographic improvement in pulmonary edema. } \\
\text { Gradual resolution of LA thrombus and survival to BivAD }\end{array}$ \\
\hline Hacking & $\begin{array}{l}\text { Surgical (sternotomy) LA venting, surgical (sternotomy) LV } \\
\text { venting, fluoroscopy-guided percutaneous blade septostomy }\end{array}$ & 2015 & 49 & $\begin{array}{l}\text { Central }(n=40) \text {, } \\
\text { peripheral }(n=9)\end{array}$ & $\begin{array}{l}\text { Elective }(n=29) \text {. Emergency }(n=22) \text { left heart dilatation, pulmonary edema, intractable } \\
\text { ventricular fibrillation }\end{array}$ & $\begin{array}{l}\text { Elective left heart decompression was associated with reduced ECMO duration (but not } \\
\text { survival) versus emergency decompression in non-cardiac patients }\end{array}$ \\
\hline Hlavacek & TTE-guided percutaneous transseptal cannulation & 2005 & 1 & Peripheral & $\begin{array}{l}\text { ME showing LA distention and impaired LVEF, CXR evidence of severe pulmonary } \\
\text { edema }\end{array}$ & $\begin{array}{l}\text { Reduction in LA distention, radiographic resolution of pulmonary edema, survival to heart } \\
\text { transplant. Advantages of LA cannulation, and disadvantages of transseptal stenting, balloon } \\
\text { and blade septostomy are discussed }\end{array}$ \\
\hline Johnston & TEE-guided atrial septostomy with sequential balloon dilatation & 1999 & 1 & Peripheral & $\begin{array}{l}\text { TE showing severe left heart dilatation, LA thrombi, and LV dysfunction, clinical and } \\
\text { CXR evidence of severe pulmonary haemorrhage and edema }\end{array}$ & $\begin{array}{l}\text { Resolution of pulmonary haemorrhage, improvement of pulmonary edema, improved LA } \\
\text { pressures. End organ damage resulting in death by day } 1 \text { admission. Advantages of this } \\
\text { appproach over simple ballooo or blade septostomy are discussed }\end{array}$ \\
\hline Kim & $\begin{array}{l}\text { Fluoroscopy-guided percutaneous balloon atrial septostomy and } \\
\text { transseptal cannulation }\end{array}$ & 2016 & 1 & Peripheral & $\begin{array}{l}\text { ME showing left heart distention, LVEF }<10 \% \text {, and clinical evidence of pulmonary } \\
\text { edema }\end{array}$ & $\begin{array}{l}\text { Recovery of LV function to LVEF } 65 \% \text {, linical and radiographic improvement in pulmonary } \\
\text { edema }\end{array}$ \\
\hline Koenig & TTE-guided blade septostomy, or balloon atrial septostomy & 1993 & 4 & NR & TE showing LA distention, and pulmonary edema & $\begin{array}{l}\text { Reduction in pulmonaray arterial and LA pressure, and A A diliatataion. Improved LV function. } \\
\text { Survival in } 3 / \text { papatients. ASD with moderate left to right shunt in } 2 \text { patients. Advantages of } \\
\text { balloon septostomy are discussed }\end{array}$ \\
\hline Kredel & $\begin{array}{l}\text { Fluoroscopy-guided percutaneous atrial septostomy and } \\
\text { transseptal cannulation }\end{array}$ & 2017 & 1 & Peripheral & TTE showing severe LV impairment and failure of AV to open & Reduction in LV distention, gradual improvement in LVEF. Nil significant residual ASD \\
\hline Sandrio & TTE-guided surgical (sternotomy) transpulmonary LV vent & 2014 & 8 & Central & $\begin{array}{l}\text { Elective }(n=6) \text { ). Emergency }(n=2) \text { TE showing LV dilatation, clinical and radiographic } \\
\text { evidence of early pulmonary edema }\end{array}$ & $\begin{array}{l}\text { Reduction in LV distention, clinical and radiographic improvement in pulmonary edema. Survival } \\
\text { in } 6 / 8 \text { patients. Intraoperative TEE suggested that better LV decompression was obtained when } \\
\text { the vent was placed in the LV versus LA. Importance of adequate vent diameter, particularly to } \\
\text { prevent in-line thrombosis, was reinforced }\end{array}$ \\
\hline Swartz & $\begin{array}{l}\text { TEE-guided percutaneous septostomy and transseptal } \\
\text { cannulation }\end{array}$ & 2012 & 1 & Peripheral & TEE showing left heart distention, and decreasing VA-ECMO circuit flows & $\begin{array}{l}\text { Reduction in left heart distention and improved biventricular systolic function, improvement in } \\
\text { VA-ECMO circuit flows. Survival to discharge }\end{array}$ \\
\hline Veeram Reddy & Fluoroscopy-guided transseptal puncture and atrial stenting & 2015 & 1 & Peripheral & $\begin{array}{l}\text { Worsening cardiac output with evidence of LA distention and ventricular arrhythmia } \\
\text { (unspecified) }\end{array}$ & $\begin{array}{l}\text { Recovery of LV function, resolution of ventricular arrhythmia. Transcatheter removal of stent } \\
\text { with complete resolution of ASD and survival to discharge }\end{array}$ \\
\hline Vlasselaers & TTE-guided insertion of Impella LP 2.5 & 2006 & 1 & Peripheral & $\begin{array}{l}\text { TOE showing LV distention and impairment with severe MR, clinical and CXR evidence } \\
\text { of severe pulmonary edema }\end{array}$ & $\begin{array}{l}\text { Improvement in haemodynamic status and clinical and radiographic appearance of pulmonary } \\
\text { edema. Monitored for haemolysis. Death from septic shock }\end{array}$ \\
\hline Ward & $\begin{array}{l}\text { TEE-guided percutaneous septostomy and transseptal } \\
\text { cannulation }\end{array}$ & 1995 & 1 & Peripheral & $\begin{array}{l}\text { Echocardiography showing left heart distention, LV impairment, LA and LV thrombi, } \\
\text { and severe MR, and clinical evidence of severe pulmonary edema }\end{array}$ & $\begin{array}{l}\text { Improved LV function, resolution of intracardiac thrombi with thrombolysis administered through } \\
\text { the transseptal cannula, and improved MR. Survival to discharge }\end{array}$ \\
\hline
\end{tabular}

